\title{
BROOKHIOUEN
}

NATIONAL LABORATORY

\section{Methane Hydrate Studies: Delineating Properties of Host Sediments to Establish Reproducible Decomposition Kinetics}

\author{
Devinder Mahajan, ${ }^{1}$ Phillip Servio, ${ }^{2}$ Keith W. Jones, ${ }_{5}^{3}$ Huan Feng, ${ }^{4}$ and \\ William J. Winters
}

${ }^{1}$ Energy Sciences and Technology Department, Brookhaven National Laboratory, Upton, NY 11973-5000 USA and Department of Materials Science and Engineering, Stony Brook University, Stony Brook, NY 11794 USA

${ }^{2}$ Department of Chemical Engineering, McGill University, Montreal, Quebec, H3A 2B2, Canada

${ }^{3}$ Laboratory for Earth and Environmental Sciences, Environmental Sciences Department, Brookhaven National Laboratory, Upton, New York 11973-5000 USA

${ }^{4}$ Department of Earth and Environmental Studies, Montclair State University, Upper

Montclair, New Jersey 07043 USA

${ }^{5}$ U.S. Geological Survey, Woods Hole, MA 02543 USA

To be published in "Advances in the Studies of Gas Hydrates"

Kluwer Academic Publishers, Inc.

December 2003

\author{
Brookhaven National Laboratory \\ P.O. Box 5000 \\ Upton, NY 11973-5000 \\ www.bnl.gov \\ Managed by \\ Brookhaven Science Associates, LLC \\ for the United States Department of Energy under \\ Contract No. DE-AC02-98CH10886
}

This is a preprint of a paper intended for publication in a journal or proceedings. Since changes may be made before publication, this preprint is made available with the understanding that it will not be cited or reproduced without the permission of the author. 


\section{DISCLAIMER}

This report was prepared as an account of work sponsored by an agency of the United States Government. Neither the United States Government nor any agency thereof, nor any of their employees, nor any of their contractors, subcontractors or their employees, make any warranty, express or implied, or assumes any legal liability or responsibility for the accuracy, completeness, or any third party's use or the results of such use of any information, apparatus, product, or process disclosed, or represents that its use would not infringe privately owned rights. Reference herein to any specific commercial product, process, or service by trade name, trademark, manufacturer, or otherwise, does not necessarily constitute or imply its endorsement, recommendation, or favoring by the United States Government or any agency thereof or its contractors or subcontractors. The views and opinions of author's expresses herein do not necessarily state to reflect those of the United States Government or any agency thereof. 


\title{
Methane Hydrate Studies: Delineating Properties of Host Sediments to Establish Reproducible Decomposition Kinetics
}

\author{
Devinder Mahajan $^{1 *}$, Phillip Servio ${ }^{2}$, Keith W. Jones ${ }^{3}$, Huan Feng ${ }^{4}$, and William J. Winters ${ }^{5}$ \\ ${ }^{1}$ Energy Sciences and Technology Department, Brookhaven National Laboratory, Upton, NY \\ 11973-5000 USA and Department of Materials Science and Engineering, Stony Brook \\ University, Stony Brook, NY 11794 USA \\ ${ }^{2}$ Department of Chemical Engineering, McGill University, Montreal, Quebec, H3A 2B2, Canada \\ ${ }^{3}$ Laboratory for Earth and Environmental Sciences, Environmental Sciences Department, \\ Brookhaven National Laboratory, Upton, New York 11973-5000 USA \\ ${ }^{4}$ Department of Earth and Environmental Studies, Montclair State University, Upper Montclair, \\ New Jersey 07043 USA \\ ${ }^{5}$ U.S. Geological Survey, Woods Hole, MA 02543 USA \\ * Corresponding author: Tel.:(631) 344-4985; dmahajan@bnl.gov
}

Key words: methane hydrate, decomposition kinetics, computed microtomography, host sediments.

\begin{abstract}
The use of methane hydrate as an energy source requires development of a reliable method for its extraction from its highly dispersed locations in oceanic margin sediments and permafrost. The high pressure (up to $70 \mathrm{MPa}$ ) and low temperature $\left(272{ }^{\circ} \mathrm{K}\right.$ to $278{ }^{\circ} \mathrm{K}$ ) conditions under which hydrates are stable in the marine environment can be mimicked in a laboratory setting and several kinetic studies of pure methane hydrate decomposition have been reported. However, the effect of host sediments on methane hydrate occurrence and decomposition are required to develop reliable hydrate models. In this paper, we describe methods to measure sediment properties as they relate to pore-space methane gas hydrate. Traditional geotechnical techniques are compared to the micrometer level by use of the synchrotron Computed Microtomography (CMT) technique. CMT was used to measure the porosity at the micrometer level and to show pore-space pathways through field samples. Porosities for three sediment samples: one from a site on Georges Bank and two from the known Blake Ridge methane hydrate site, from different depths below the mud line were measured by traditional drying and by the new CMT techniques and found to be in good agreement. The integration of the two analytical approaches is necessary to enable better understanding of methane hydrate interactions with the surrounding sediment particles.
\end{abstract}

\section{Introduction}

Methane hydrates represent a potentially important alternative energy source. However, recovery is difficult since they are typically found in deep ocean subbottom sediments. Our aim 
here is to briefly review general information on hydrate research and to summarize cogent information on the geotechnical properties of the oceanic sediments in which they are found. We present results obtained using standard measurement techniques in combination with results of experiments using high-spatial resolution synchrotron computed microtomography to obtain information at the grain-size scale. We use grain-size measurements to predict the macroscopic geotechnical properties of the sediments. Such a development can be widely used in developing an economical method for commercial recovery of methane from hydrate.

\section{Summary of Relevant Previous Work}

Methane hydrate belongs to a general class of inclusion compounds commonly known as clathrate hydrates. Clathrate hydrates owe their existence to the ability of $\mathrm{H}_{2} \mathrm{O}$ molecules to assemble via hydrogen bonding and form polyhedral cavities that serve as hosts to gas (guest) molecules. Of over 130 compounds (guest molecules) that form clathrate hydrates, those involving natural gas is of crucial importance due to its potential as an energy resource and geohazard. Natural gas is the cleanest of all known fossil fuels and its importance as a primary energy carrier is well established. Gas hydrates, the most common being methane hydrate $\left(\mathrm{CH}_{4} \cdot \mathrm{nH}_{2} \mathrm{O}\right.$ where $\left.\mathrm{n} \geq 5.75\right)$ form readily as crystalline solids under certain conditions of relatively high pressure and low temperature (1). During deep-ocean drilling for natural gas such temperature and pressure conditions are frequently encountered under which facile formation of hydrates result in pipeline plugging that makes natural gas hydrate a nuisance and expensive problem. However, recent estimates (2) indicate that naturally occurring methane hydrates could become the next energy frontier if an economical and environmentally acceptable method to extract methane could be developed.

The development of an economic hydrate dissociation method requires an understanding of its kinetic stability and physical properties. Moreover, sediments that are host to methane hydrate may also influence its stability. Several kinetic studies have been carried out on laboratory prepared synthetic samples $(3,4,5,6)$ but the study of host sediments has received less attention. In previously reported studies among others, several workers $(7,8,9)$ employed the tomographic technique using industrial type scanners with conventional tube-type $\mathrm{x}$-ray sources. Typical voxel sizes for these measurements were $0.6 \times 0.6 \times 1.0 \mathrm{~mm}^{3}(8)$ and $0.2 \times 0.2 \times 1.0 \mathrm{~mm}^{3}$ (9). In reference 7 , the frequency of computed tomography (CT) values were determined by arbitrary assigning unitless value of 0 to pure water. The corresponding CT values were $\sim+400$, $\sim-100$, and $\sim-150$ to -275 for dry ice, ice, and methane hydrate. This scale provides a useful reference to correlate experimentally measured CT data. Since the CT values are density dependent, the value for sediments usually exceed +1000 and the value for common gases such as $\mathrm{CH}_{4}$ is extremely small (-1000). A subsequent study measured the dissociation of natural gas hydrate samples from the Mallik-2L-38 gas hydrate research well in Mackenzie Delta, Canada that were obtained from the depth of $913.76 \mathrm{~m}$ and stored at $243 \mathrm{~K}$ after pressurization with 6.0 $\mathrm{MPa} \mathrm{N}_{2}$ gas $(8,9)$. Assuming estimated $30 \%$ porosity of the host sand and cage occupancy of $\sim$ $80 \%$, the hydrate dissociation front was scanned as a function of time when the temperature was raised from $255 \mathrm{~K}$ to $277 \mathrm{~K}$. The well-resolved images showed that the sample dissociated at the exposed surface as well as within the interior (pore spaces) in response to a stepped decrease of $0.1 \mathrm{MPa}$ below the methane hydrate equilibrium pressure: this was attributed to the presence of fluids in the pore spaces. The estimated sample porosity was $25-35 \%$ and gas hydrates were 
observed in intergranular pore space. The same group modeled the CT data by applying the Stefan moving boundary model to track the time-dependent methane hydrate dissociation progression in a laboratory prepared cylindrical synthetic methane hydrate/sand sample. The model using one-dimensional heat flow theory was applied with a simple assumption of constant boundary temperature. The estimated thermal conductivity value for the product water ice/sand mixture, at $2.6 \mathrm{~W} / \mathrm{m} \mathrm{K}$, was attributed to contribution from heat conduction, methane gas convection and the kinetic effect during dissociation. The model yielded an estimated porosity of $49.5 \%$ for the synthetic methane hydrate/sand sample.

It is clear that host sediment affects the formation/decomposition stability of methane hydrate as well as the methane content by controlling pore-space filling. In the above described study [8], it was noted that samples obtained from the Mallik well at the depth of $886-952 \mathrm{~m}$ (beneath the permafrost zone), gas hydrates were primarily observed in fine to coarse-grained sands and were rarely, if ever, found in finer-grained silts and clays (10). Therefore, it is crucial to understand the properties of host sediments.

We recently reported the first CMT study of a sediment sample taken at a depth of 667 meters from the Blake Ridge methane hydrate site that allowed us to resolve the sediment structure at the micrometer level (11). The reported study complemented other reported CT studies (7-9). We report here on the continuation of our CMT study in order to delineate host sediment properties along with relevant data from previous geotechnical measurements.

\section{Experimental}

Table 1 lists the origin of three host sediment samples. The selected sediments were taken at 0.2 meters, 49.6 meters, and 666.7 meters below the mud line. Whole-round sub samples obtained during Ocean Drilling Program Leg 164 on the Blake Ridge (49.6 m and 666.7 $\mathrm{m})$ and $\mathrm{OC} 178$ on Georges Bank $(0.2 \mathrm{~m})$ were preserved in the original liner, capped, completely covered in wax, and subsequently stored in a refrigerator at a temperature of approximately $4^{\circ} \mathrm{C}$. Water content values were determined according to American Society for Testing and Materials (ASTM) Standard D 2216-92 (12) except that the drying temperature was $90^{\circ} \mathrm{C}$.

Table 1. Identification and location of samples used in the present study

\begin{tabular}{|c|c|c|c|c|c|}
\hline $\begin{array}{c}\text { Sample } \\
\text { No. }\end{array}$ & Cruise & Latitude & Longitude & Hole/core & $\begin{array}{c}\text { Water Depth } \\
\mathrm{m}\end{array}$ \\
\hline BLR-0.1 & OC178 & $41^{\circ} 51.5^{\prime} \mathrm{N}$ & $68^{\circ} 18.1^{\prime} \mathrm{W}$ & $27-\mathrm{GC} 2$ & 222 \\
\hline BLR-50 & ODP leg 164 & $31^{\circ} 48.210^{\prime} \mathrm{N}$ & $75^{\circ} 31.343^{\prime} \mathrm{W}$ & $995 \mathrm{~A}-7 \mathrm{H}-1$ & 2278.5 \\
\hline BLR-667 & ODP leg 164 & $31^{\circ} 48.210^{\prime} \mathrm{N}$ & $75^{\circ} 31.343^{\prime} \mathrm{W}$ & $995 \mathrm{~A}-80 \mathrm{X}-1$ & 2278.5 \\
\hline
\end{tabular}

Grain size distributions were measured using a laser light-scattering technique [MicroTrac, Inc., North Largo, FL 33773]. This -method was especially useful because of its 
ability to produce very detailed information on the distributions that are impossible to obtain using traditional sieving methods.

The investigation of the sediment microstructure was carried out using the CMT apparatus at the NSLS beam line X-27A. Synchrotron radiation provides a very high intensity $\mathrm{x}$ ray beam with a continuous energy distribution and its properties are well adapted to study materials such as sediments, sand, limestone, and rock samples. This is illustrated in Figure 1 where values for the brilliance of $\mathrm{x}$-ray beams produced at several synchrotron facilities worldwide are displayed and compared to those found for $\mathrm{x}$-ray tube values. Values for synchrotron are several orders-of-magnitude higher than those for conventional sources. The work reported here is based on use of a bending magnet at the Brookhaven National Synchrotron Light Source (NSLS).

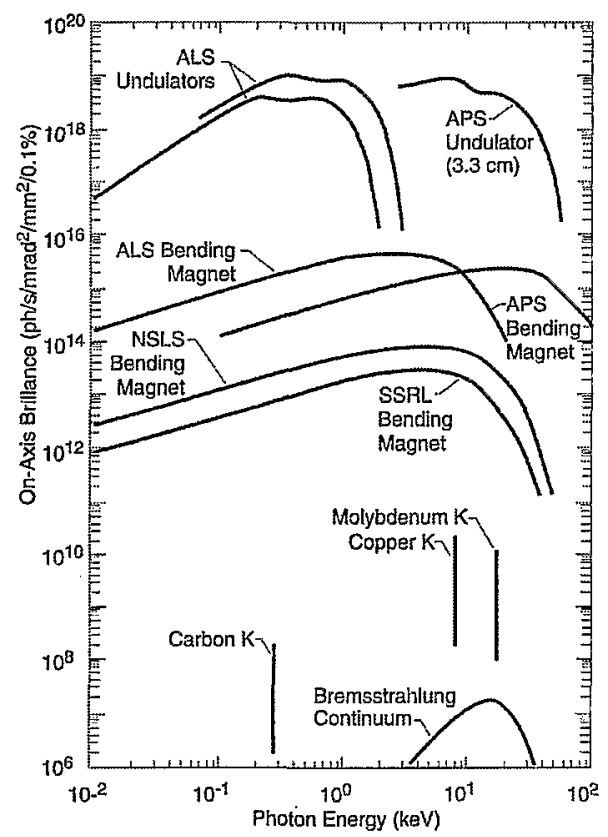

Figure 1. X-ray brilliance produced at the NSLS-BNL, APS-ANL, ALS-LBNL and the European Synchrotron Radiation Facility (ESRF). Comparison is also made to conventional Xray sources. (From Jones et al. Ref. 13).

For the present CMT experiment, we used a third-generation approach where the entire sample is exposed to the $\mathrm{x}$-ray beam and the transmitted beam is detected with a scintillator-area detector combination. Exposures are then made as the sample is rotated through $180^{\circ}$. The X-ray beam energy for the measurements were $25 \mathrm{KeV}$. The data collection procedure is as follows. Typically, an area beam with a size of about $6 \mathrm{~mm}$ in the horizontal and about $1 \mathrm{~mm}$ in the vertical is used to illuminate the sample and air surrounding it. The $\mathrm{x}$-rays are detected with a YAG scintillator that is viewed by a CCD camera. The complete tomographic data set consists of roughly 2000 exposures taken as the sample is rotated through 180 degrees in 0.09 -degree 
increments. The tomographic volume is then computed using a Fast-Fourier Transformation (FFT) method as developed by Dowd et al. (14). Data acquisition and processing both require about 2 to 3 hours each. Voxel sizes employed in this experiment were $0.068 \mathrm{~mm}$. A schematic diagram of the apparatus is given in Figure 2.

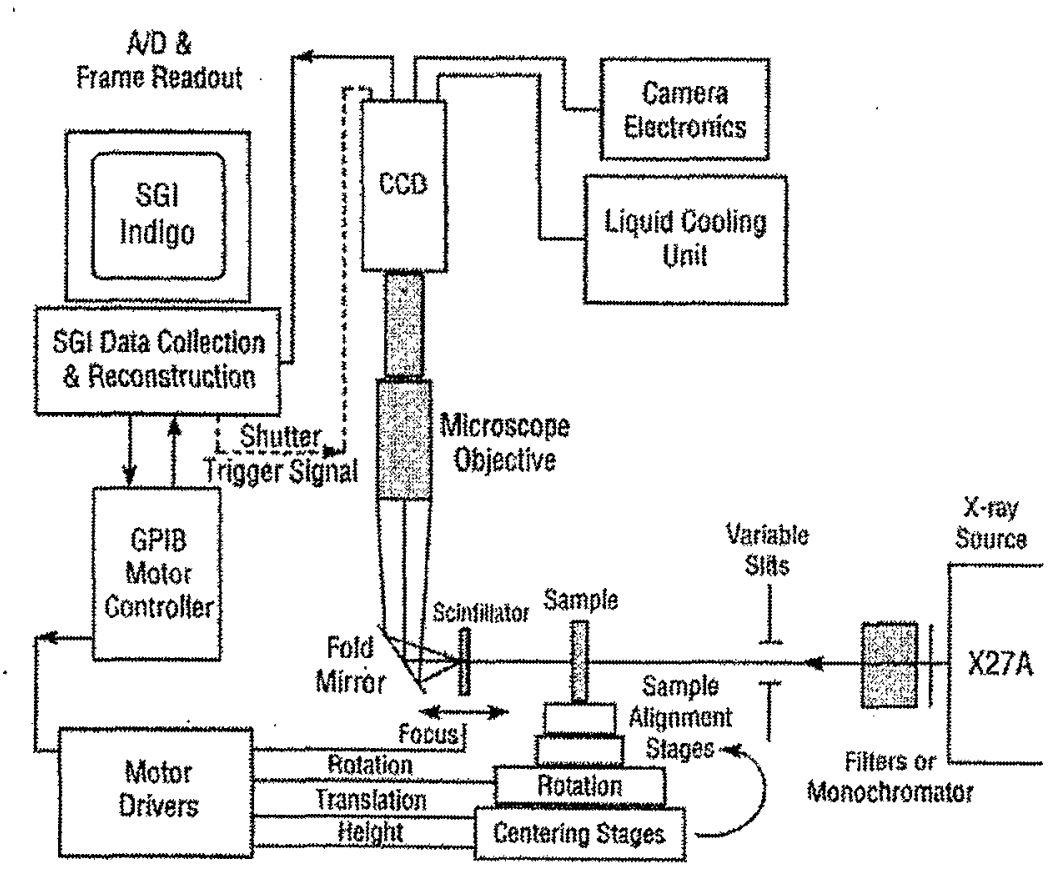

Figure 2. Schematic diagram of the major components in the CMT apparatus used at the X27A NSLS bending magnet beam line (From Jones et al. Ref. 13).

\section{Results and Discussion}

\section{Measurement of Bulk-sediment Samples:}

Winters (15) conducted an extensive investigation of the geotechnical properties of sediments from the Blake Ridge and from Georges Bank that helps to define the engineering behavior of the materials. Results include values for water content, porosity, liquid and plastic limits, liquidity and plasticity indices, vane and remolded vane shear strengths, sensitivity and pocket penetrometer shear strength. These results are shown in Table 2.

The porosity of the sediments can be found using conventional methods in which water content is calculated by taking the ratio of the mass of water evaporated during the drying process/mass of solids remaining after drying. After correction for the presence of salt in the pore fluid, porosity is determined from the volume of pore space occupied by the water phase/total specimen volume assuming complete pore space water saturation. Density of the sediment grains 
was determined using a helium gas pycnometer, Porosity decreases substantially with depth, however, even at $667 \mathrm{~m}$ below the sediment surface, the porosity is still $51 \%$ (Table 2). We compare these values to those obtained from CMT below. Values found for the porosity as a function of depth below the surface are shown in Figure 3.

Table 2. Summary of geotechnical evaluations of sediment samples from the Blake Ridge (Data from Ref. 15).

\begin{tabular}{|c|c|c|c|c|}
\hline $\begin{array}{c}\text { Sample } \\
\text { No. }\end{array}$ & $\begin{array}{c}\text { Sub bottom } \\
\text { depth } \mathrm{m}\end{array}$ & $\begin{array}{c}\text { Water content } \\
\text { (Mw/M solids), } \%\end{array}$ & $\begin{array}{c}\text { Porosity } \\
\%\end{array}$ & $\begin{array}{c}\text { Maximum past stress } \\
\mathrm{kPa}\end{array}$ \\
\hline BLR-0.1 & 0.2 & 141 & 79.2 & 4.2 \\
\hline BLR-50 & 49.57 & 87.9 & 70.0 & 205 \\
\hline BLR-667 & 666.85 & 39.3 & 51.0 & 2730 \\
\hline
\end{tabular}

Figure 3. Porosity vs. depth derived from air drying of the Blake Ridge sediment sample. (From W. Winters, reference 14).

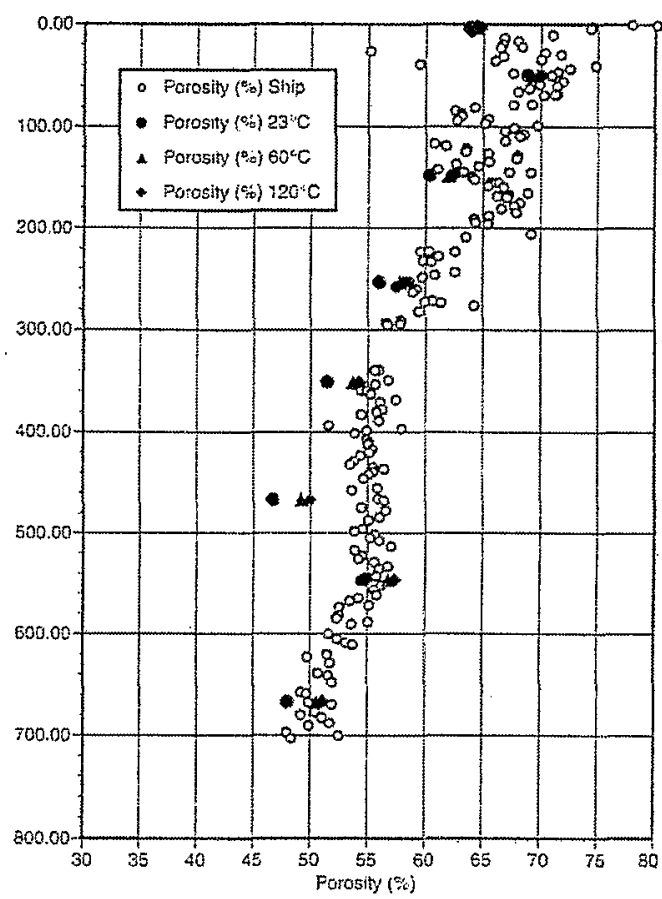

\section{Measurements on the grain-size scale}

The particle distribution in terms of grain size for our three test samples are shown in Figure 4. Although all three specimens contain substantial amounts of fine-grained sediments, they also have grains of relatively large diameters that are greater than 25 micrometers and show the presence of substantial amounts of sand. The finer particles appear to be separable into two distinguishable size components. 


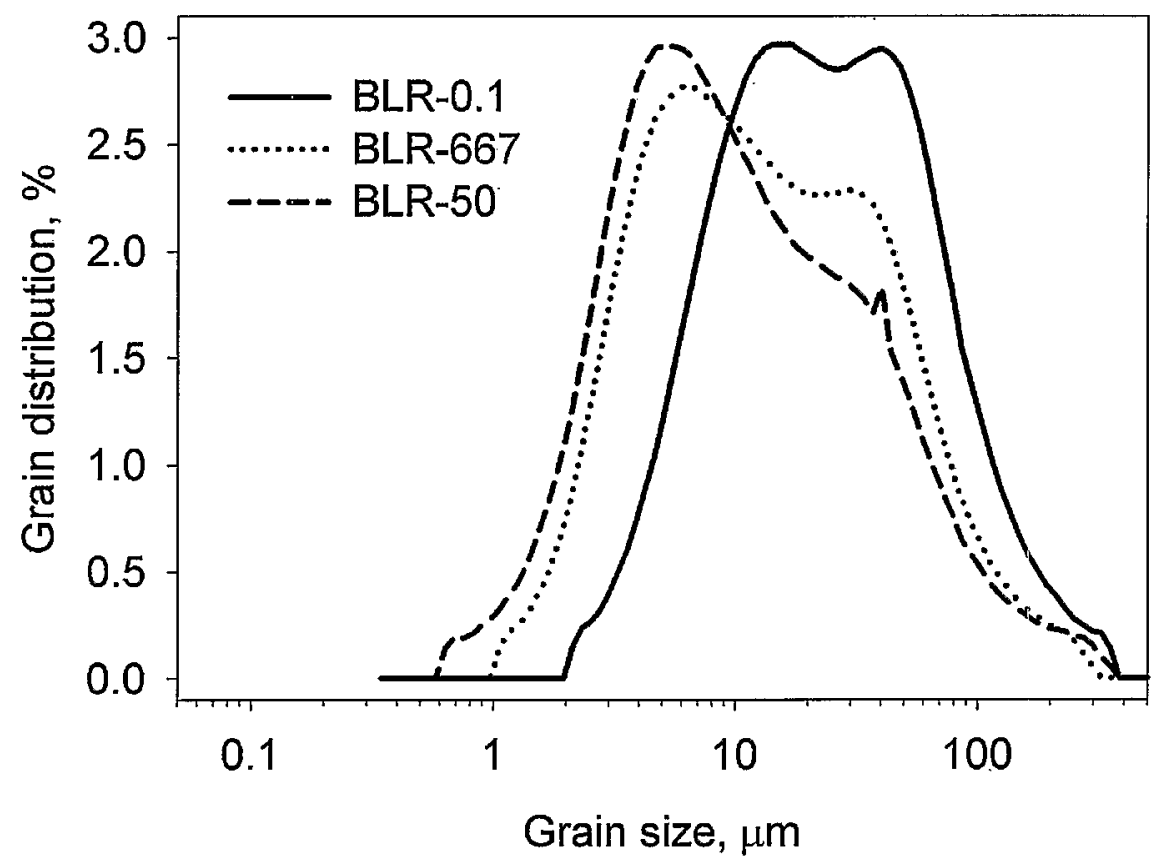

Figure 4. Grain-size distributions measured for the three samples.

\section{CMT measurements}

The CMT technique is suitable for investigation of samples with a size less than $10 \mathrm{~mm}$ in the horizontal direction for the experiments. In this experiment, measurements were made on three samples, BLR-0.1, BLR-50, and BLR-667, obtained at depths of $0.1 \mathrm{~m}, 49.6 \mathrm{~m}$, and 666.7 $\mathrm{m}$, respectively.

The CMT measurements produce a 3-D matrix representing the X-ray attenuation coefficients found for voxels contained in a volume of the sediment with $\mathrm{x}, \mathrm{y}, \mathrm{z}$ coordinates. We used software developed by Lindquist (16) to segment the voxels into solid and pore space categories. Plots of the histograms found for the attenuation coefficients and values for the porosity as a function of the attenuation coefficient are given in Figure 5. The Lindquist program uses image analysis algorithms in making assignments between the two phases based on values of the coefficients found for neighboring voxels.

Following the segmentation of the data into pore and solid phases, we can display the data either as 2-dimensional sections or as 3-dimensional volumes. Typical results found for the 2-dimensional section are given in Figure 6. Displays for the 3-dimensional volumes are given in Figure 7. 

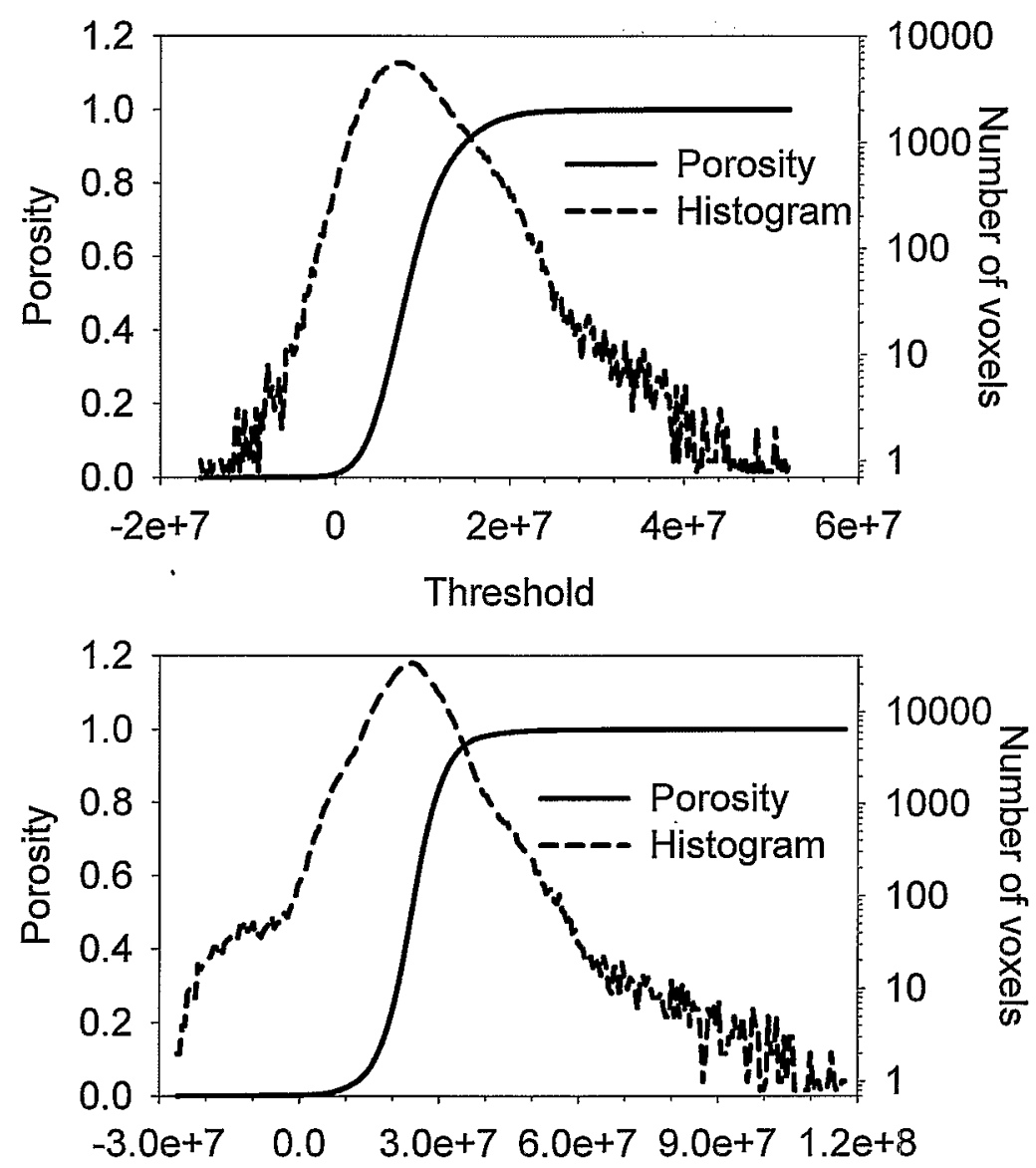

Threshold

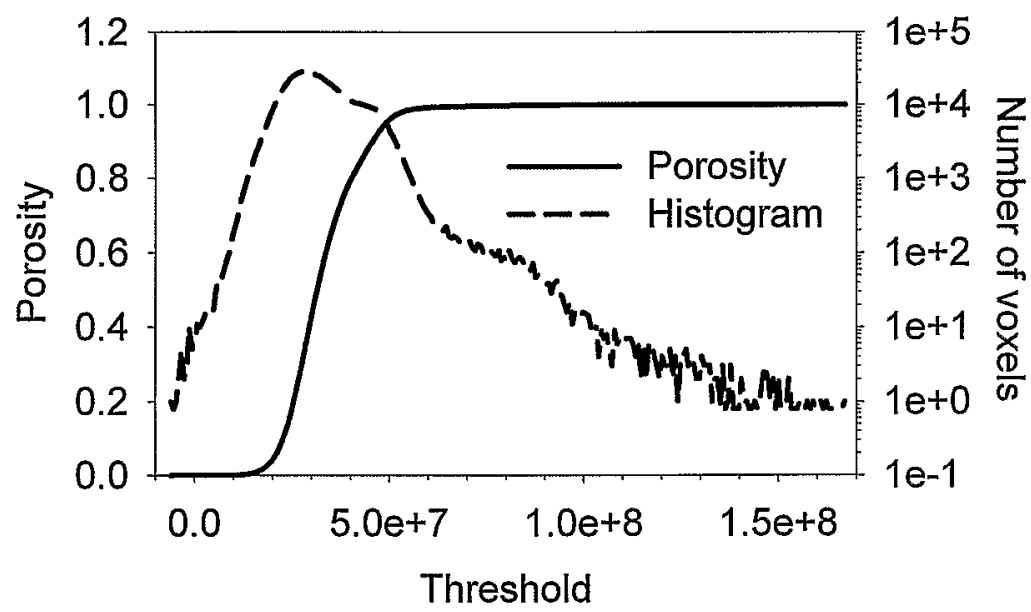

Figure 5. Porosities and histograms showing the distribution of attenuation coefficients in the tomographic volumes for the three samples measured. Samples BLR-0.1 (top), BLR-50 (middle) and BLR-667 (bottom). 


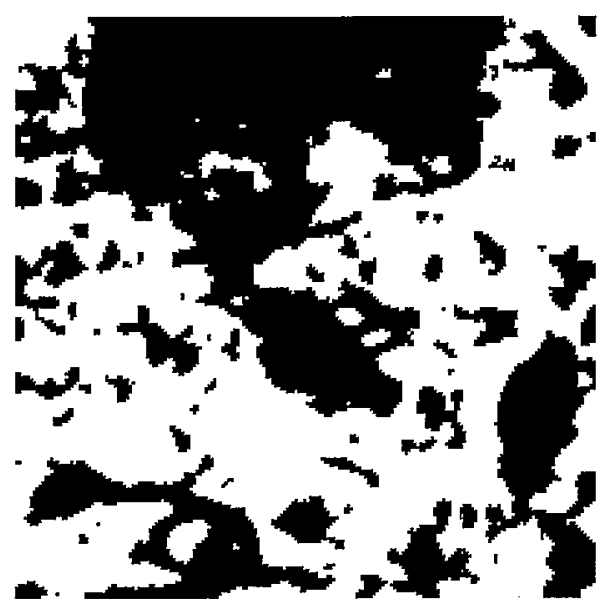

ODP-164, BR $\% 8,668.85 \mathrm{~m}$

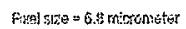

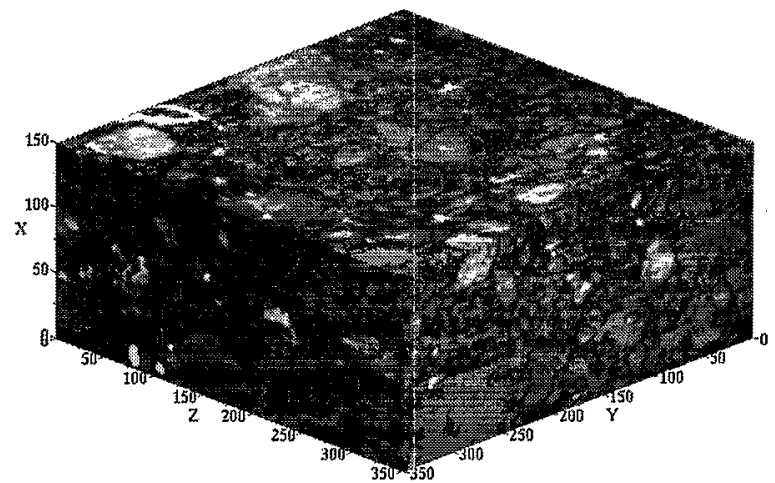

Figure 6 (Left). A 2-D image of a segmented slice reconstructed from the CMT data of sample BLR-50 from a depth of $49.6 \mathrm{~m}$. The image size is $200 \times 200$ pixels ( 1 pixel $=6.8$ micrometer). Pore space is shown in white and solids in black. Figure 7 (Right). Volume CMT image of sediment sample BLR-668. The pixel size is $.0068 \mathrm{~mm}$. The Green to Purple to Yellow show increased attenuation in the measured attenuation coefficients indicating materials of increasing. The light green color represents pore space.

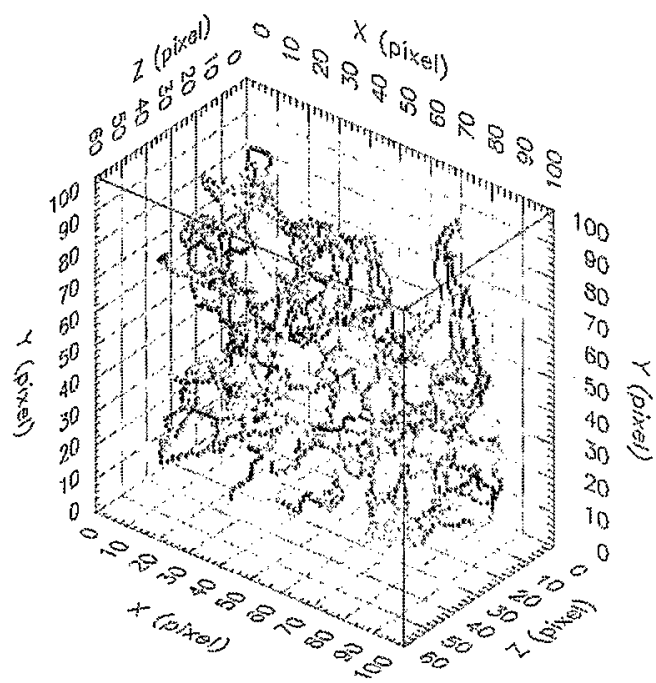

Figure 8. Pathways reconstructed from the data such as in Figure 7. Clockwise from left: Samples BLR-0.1, BLR-50, and BLR-668. Colors show different sizes for the pathways. The pixel sizes for the three axes are $.0068 \mathrm{~mm}$.
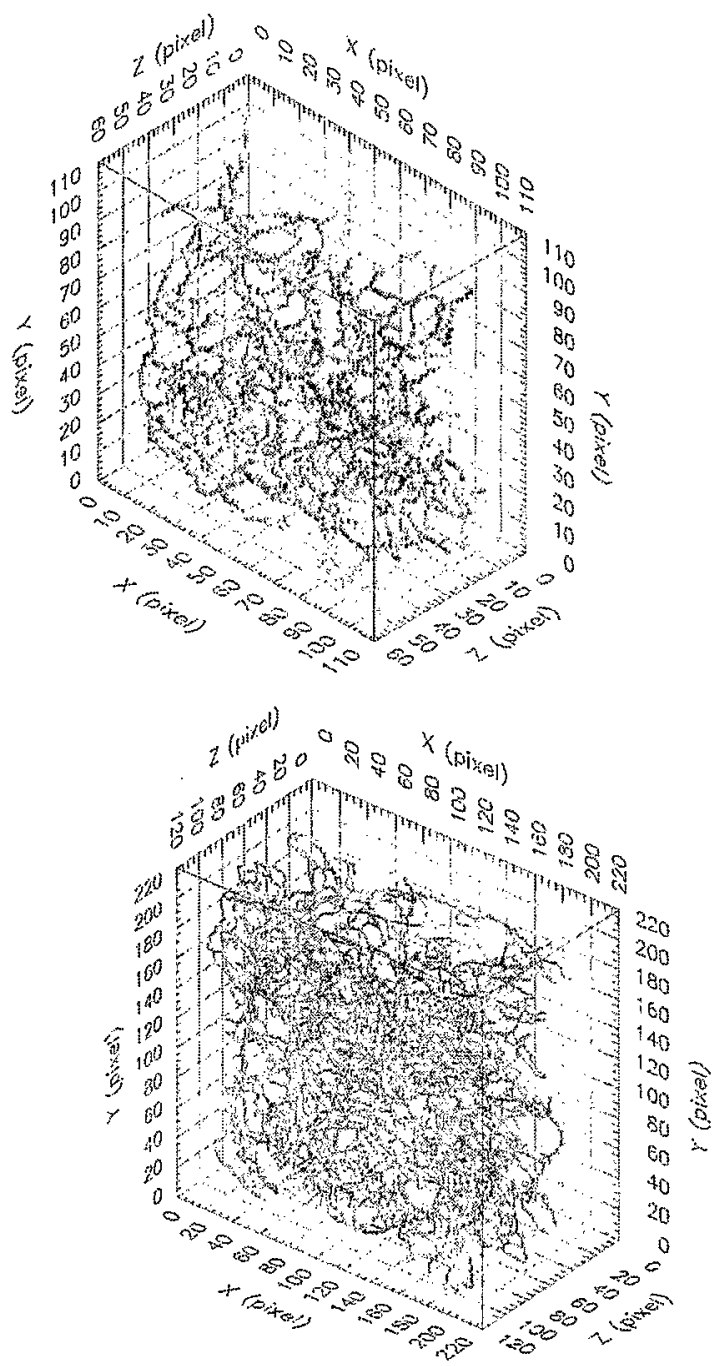
We stress that the CMT process is non-destructive and that sequential measurements can be made on a given sample as conditions of temperature and volume are changed. For example, porosity can be measured as a function of the stress (pressure) applied to the sample.

The values found for the porosities in the three samples measured are compared with the values determined via the mass measurements by Winters (15) in Table 3 . As expected, porosity decreases with depth but the trend is not linear. This agreement between the different methods is evidence for the validity of CMT measurements. The pathways shown in Figure 8 differ greatly from one specimen to another and may depend on the state of the materials. Studies are now underway in which the sediment integrity will be strictly maintained in their transport and handling prior to the CMT measurements. Detailed interpretation of the CMT data will be the subject of a subsequent paper.

\section{Table 3. Comparison of porosity values for the three samples determined by weight and CMT measurements.}

\begin{tabular}{|c|c|c|}
\hline Sample No. & $\begin{array}{c}\text { \% Porosity } \\
\text { Conventional }\end{array}$ & $\begin{array}{c}\text { \% Porosity } \\
\text { CMT method }\end{array}$ \\
\hline BLR-0.2 & 79.2 & 80.7 \\
\hline BLR-50 & 70.0 & 64.3 \\
\hline BLR-667 & 51.0 & 58.1 \\
\hline
\end{tabular}

\section{Conclusions}

We have presented a summary of measurements on the physical properties of sediments relevant to methane hydrate recovery. The data includes not only geotechnical determinations, but also the CMT data that gives porosity values and pathways through the sediment material. The results show that CMT techniques can be used to study sediment properties on a micrometer-size scale. Since the technique is non-destructive, changes in the sediment microstructures as a function of pressure and temperature can be measured. It is also feasible to look at formation of methane hydrates in the sediment structure as has already been demonstrated (7-9). A longer term challenge is to start from the microscale data and calculate the macroscopic quantities shown in Table 2. We also note that the CMT measurements help in identification of different minerals found in the sediments. This feature of CMT was not exploited in this survey.

\section{Acknowledgements}

This research was, in part, supported by the US Department of Energy Contract No. DEAC02-98CH10886 (KWJ, DM, HF). Additional support was provided through the Laboratory Directed Research and Development (LDRD) program at Brookhaven National Laboratory. We thank Professor Brent Lindquist, Stony Brook University for helpful discussions and assistance regarding the 3-D images. The authors wish to thank the captain and crew of the JOIDES 
Resolution and the R/V Oceanus, as well as the Ocean Drilling Program, for providing the sediment samples upon which this study was based.

\section{References}

(1) Clathrate Hydrates of Natural Gases, $2^{\text {nd }}$ edition; Sloan, Jr., E. D. Ed.; Marcel Decker, New York, 1998.

(2) Dickens, G. R.; Paull, C. K.; Wallace, P. Nature. 1997, 385, 426.

(3) Makogon, Y. E.; Holditch, S. A. Oil \& Gas J. 2001, 99(6), 47.

(4) Makogon, Y. E.; Holditch, S. A. Oil \& Gas J. 2001, 99(7), 45.

(5) Natarajan, V.; Bishnoi, P.R.; Kalogerakis, N. Chem. Eng. Sci., 1994, 49(13), 2075.

(6) Englezos, P.; Kalogerakis, N.; Dholabhai, P.D.; Bishnoi, P.R. Chem. Eng. Sci., 1987, 42(11), 2647.

(7) Mikami, J.; Masuda, Y.; Uchida, T.; Satoh, T.; Takeda, H. In Gas Hydrates, Challenges for the Future, Holder, G.D.; Bishnoi, P. R., eds. Annal. N.Y.A.S. 2000, 912, 1011.

(8) Tomutsa, L.; Freifeld, B.; Kneafsey, T. J.; Stern. L. A. Soc. Petrol. Engineer. (S PE$75533,2002$.

(9) Uchida, T.; Dallimore, S.; Mikami, J. In Gas Hydrates, Challenges for the Future, Holder, G.D.; Bishnoi, P. R., eds. Annal. N.Y.A.S. 2000, 912, 1021.

(10) Winters, W.J., Dallimore, S.R., Collett, T.S., Katsube, T.J., Jenner, K.A., Cranston, R.E., Wright, J.F., Nixon, F.M., and Uchida, T., 1999, Physical properties of sediments from the JAPEX/JNOC/GSC Mallik 2L-38 gas hydrate research well: in Dallimore, S.R., Uchida, T., and Collett, T.S., eds., Scientific Results from JAPEX/JNOC/GSC Mallik 2L-38 Gas Hydrate Research Well, Mackenzie Delta, Northwest Territories, Canada, Geological Survey of Canada Bulletin 544, p. 95-100.

(11) Jones, K. W.; Feng, H.; Winters, W. J.; Servio, P.; Mahajan, D. Amer. Mineral. submitted (12) American Society for Testing and Material, 1997. Annual Book of ASTM standards, Vols. 04.08 and 04.09, Soil and Rock, Philadelphia (ASTM).

(13) Jones, K. W., Feng, H., Lindquist, W. B., Adler, P. M., Thovert, J. F., Vekemans, b., Vincze, L., Szaloki. I., Van Grieken, R. Adams, F. and Riekel, C. From: Mees, F., Swennen, R. Van Geet, M., and Jacobs, P. (eds) 2003. Applications of X-ray Computed Tomography in the Geosciences. Geological Society, London, Special Publications, 215, 39-49.

(14) Dowd, B.A.; Andrews, A.B.; Marr, R.B.; Siddons, D.P.; Jones, K.W.; Peskin, A.M. In Advances in X-Ray Analysis, Plenum Publishing Corp., New York, 1999 and references therein.

(15) Winters, W.J. Proceedings of the Ocean Drilling Program, Scientific Results (Paull, C.K.; Matsumoto, R.; Wallace P.J.; Dillon, W.P., eds.), 2000, 164, 421.

(16) Lindquist, W.B., Lee, S.M., Coker, D.A., Jones, K.W. and Spanne, P. J. Geophys. Res., 1996, 101, 8297. 